\title{
(1)
}

\section{Eddy-induced transport and kinetic energy budget in the Arabian Sea}

Peng Zhan ${ }^{1}$, Daquan Guo ${ }^{1}$, Ibrahim Hoteit ${ }^{1^{*}}$

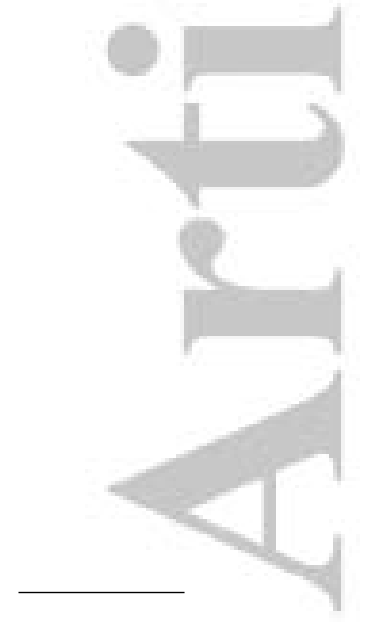

Corresponding author: Ibrahim Hoteit, Division of Physical Sciences and Engineering, King Abdullah University of Science and Technology, Thuwal, Saudi Arabia. (ibrahim.hoteit@kaust.edu.sa)

${ }^{1}$ Division of Physical Sciences and

Engineering, King Abdullah University of

Science and Technology, Thuwal, Saudi

Arabia.

This article has been accepted for publication and undergone full peer review but has not been through the copyediting, typesetting, pagination and proofreading process which may lead to differences between this version and the Version of Record. Please cite this article as doi: 10.1029/2020GL090490 
3

4

This study investigates the vertical eddy structure, eddy-induced transport, and eddy kinetic energy (EKE) budget in the Arabian Sea (AS) using an eddy-resolving reanalysis product. The EKE intensifies during summer in the western AS. Anticyclonic eddies (AEs) and cyclonic eddies (CEs) present warm-fresh and cold-salty cores, respectively, with interleaved salinity structures. The eddy-induced swirl transport is larger in the western AS and tends to compensate for heat transport by the mean flow. Zonal drift transport by AEs and CEs offset each other, and meridional transport is generally weaker. Eddies also produce notable upward heat flux during summer in the western AS, where ageostrophic circulations are induced to maintain a turbulent thermal wind balance. Plausible mechanisms for EKE production are governed by baroclinic and barotropic instabilities, which are enhanced in summer in the western basin, where signals are quantitatively one order larger than the turbulent wind inputs.

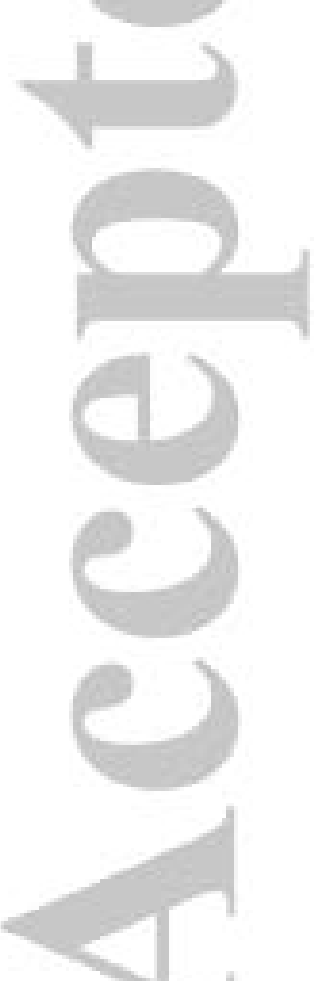




\section{${ }_{17} \quad$ Key Points}

${ }_{18}$ Main point 1: Eddy activities and eddy-induced transport play a crucial role in maintaining oceanic heat and salt conditions in the Arabian Sea.

${ }_{20}$ Main point 2: The western Arabian Sea is identified as a new hotspot in the global ocean with noticeable upward eddy-induced heat transport.

22 Main point 3: Baroclinic and barotropic instabilities are the primary sources of eddy kinetic energy in the Arabian Sea.
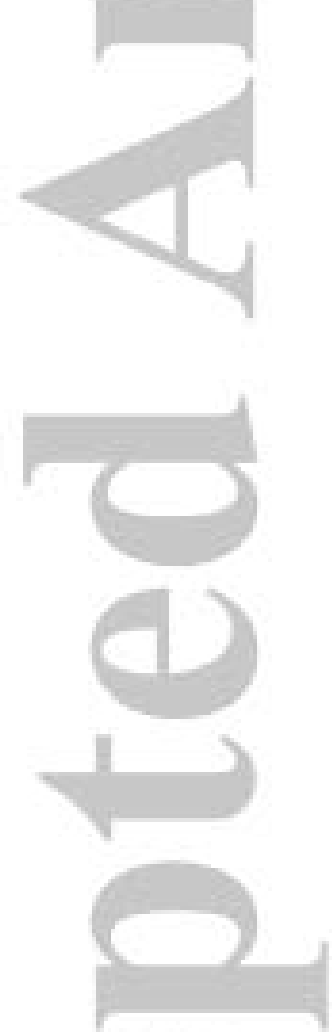
$\mathrm{X}-4$ ZHAN ET AL.: EDDY TRANSPORT AND ENERGY BUDGET

\section{Introduction}

Mesoscale eddies are one of the key components of circulation [Fischer et al., 2002] and biological processes [Sergey, 2012] in the Arabian Sea (AS), particularly in its western basin which exhibit a strong activity similar to that of other eddy-rich regions in the global ocean [Scharffenberg and Stammer, 2010; Roullet et al., 2014]. The western AS experiences seasonally reversing monsoonal winds that drive energetic spatiotemporal variability related to the Somali Current (SC), coastal upwelling, and the upper-ocean heat budget [Schott and McCreary, 2001; Fischer et al., 2002; Seo, 2017; Wang et al., 2018]. Eddy activities also exhibit strong seasonality that peaks during the summer monsoon season [Trott et al., 2018]. Wind stress [Trott et al., 2017], background currents [Trott et al., 2018], and west propagating Rossby waves [McCreary et al., 1993; Brandt et al., 2002] are qualitatively interpreted as possible factors that strengthen eddies in the region; however no consensus has been reached. These eddies drive local upwelling and downwelling [Trott et al., 2019] and could make a large contribution to the marine ecosystem and biogeochemical variability when coupled with wind-induced Ekman pumping [Seo et al., 2008; Yao and Hoteit, 2015]. More importantly, eddies transport a significant amount of oceanic properties and influence the spreading pathways of marginal sea water [Carton et al., 2012; de Marez et al., 2019]. In particular, eddies off Somalia cause variabilities in tracers and strongly impact regional transport [Trott et al., 2019], some of which may propagate into the western Gulf of Aden (GoA) and promote the transport of Red Sea water [Bower and Furey, 2012]. 
Transports by mesoscale eddies in oceans play a dominant role in regulating biological activities [Chelton et al., 2011], general circulation [Macdonald and Wunsch, 1996], and regional climate [Zhang et al., 2014]. Eddies induce two types of tracer transport. Swirl transport occurs when the tracer anomalies and rotational velocities are asymmetric and, therefore, leads to net transport over the eddy wavelength [Chelton et al., 2011; Hausmann and Czaja, 2012]; this process is sometimes enhanced by a series of flanking eddies [Zhan et al., 2016]. Drift transport is caused by the movement of eddies when tracer anomalies inside an eddy are trapped by interior water parcels and move with the eddy [Dong et al., 2014; Lin et al., 2019]. These eddy-induced transports may exhibit comparable magnitudes [Dong et al., 2014; Sun et al., 2019], and their contribution should be jointly considered. Estimating eddy-induced transport requires 3D eddy structures, which can be approximated by tracking altimeter maps and simultaneous Argo floats in data-rich regions [Qiu and Chen, 2005; Souza et al., 2011; Chen et al., 2012], utilizing a universal structure that is representative of global oceanic mesoscale eddies [Zhang et al., 2013, 2014], or as a more comprehensive alternative, analyzing outputs of an eddy-resolving model [Volkov et al., 2008; Frenger et al., 2015; Zhan et al., 2019].

Previous observational studies provided snapshots of vertical eddy structure at scattered locations in the AS [Fischer et al., 2002; Carton et al., 2012; L'Hegaret et al., 2016; Trott et al., 2018]. In a more recent study [de Marez et al., 2019], systematic 3D eddy structures in the northern AS were presented for the first time by a compositing altimeter and Argo data. The aforementioned studies used different types of observations to obtain complementary perspectives, but the spatiotemporal sparseness of the observations pro-

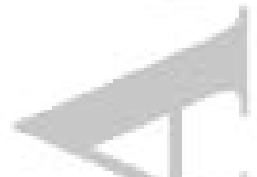

D R A F T
November $13,2020,5: 28 \mathrm{am}$
D $R A F$ T 
$\mathrm{X}-6$ ZHAN ET AL.: EDDY TRANSPORT AND ENERGY BUDGET

66 
Schott and McCreary, 2001; Chatterjee et al., 2013]. The seasonal surface forcing cycle over the AS drives strong seasonally reversal circulation in western AS [McCreary et al., 1993; Seo et al., 2008]: during winter the mean flow is southward along the Somalia coast, whereas the SC intensifies and flows northward under the summer southwest monsoon [Beal et al., 2013] and forms the Great Whirl (GW) with retroflection and structures extending northeast towards the Gulf of Oman (GoO) [Fischer et al., 2002]. EKE in the interior basin is weaker than the western basin, a general trend in world oceans [Stammer and Wunsch, 1999]. The largest summer EKE appears at $55^{\circ} \mathrm{E}$ and $7^{\circ} \mathrm{N}$, and the most intense signals exceed $5 \times 10^{4} \mathrm{~J} / \mathrm{m}^{2}$. Eddies in the AS propagate westward into the GoA, producing higher EKE during early winter (Figure 1 a) [Al Saafani et al., 2007]. Here, we further verify CMEMS EKE against that calculated using surface geostrophic currents from AVISO data (Figure $1 \mathrm{~d}$ and $\mathrm{h}$ ), which exhibit similar spatiotemporal distributions. A stricter definition to describe the intensity of mesoscale eddies is to estimate their energy from detected individual eddies (S2) as shown in Figure 1 (c) and (g). Such quantity and EKE calculated using the aforementioned mean metric deviations show good agreement, suggesting that EKE is a good approximation of actual mesoscale eddy activities; therefore, the EKE and the associated derivations of energy flux can be used to investigate internal processes and diagnose the energy budget.

Nevertheless, some insights of eddy properties still rely on detecting complete eddy fields (Figure 1 i-l). Figure 1 (i) indicates that the majority of eddies are found in the western AS and GoA. Eddies generated in the central AS propagate westward as Rossby waves and accumulate upon reaching the western basin [Al Saafani et al., 2007]. Eddies

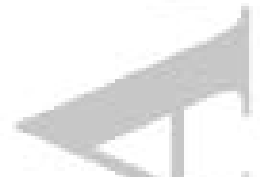

D R A F T 
can also form locally when the SC flows northward in summer and turns further northeast in large meanders [Fischer et al., 2002]. The largest and deepest eddies are found in lower latitudes, particularly the SC region (Figure $1 \mathrm{j}$ and $\mathrm{k}$ ). A large component is contributed by the anticyclonic GW developed during the summer monsoon season, which has a radius and intensity larger than most eddies in the northwestern Indian Ocean [Trott et al., 2018]. The propagation speeds of individual eddies are estimated by tracking their trajectories in sequential maps (Figure $1 \mathrm{i}$ ). Eddies generally move westward and tend to have a larger speed in the southern basin as they are embedded within the large scale Rossby waves, which propagate faster in the lower latitudes; though strong background currents in regions east of the Somalia coast can advect circular eddies along their flow axis.

\section{3D structures of mesoscale eddies}

Eddies in the AS show pronounced spatiotemporal variability but tend to exhibit a uniform structure under normalized coordinates, as reported from a global perspective [Zhang et al., 2013]. Figure 2 illustrates the generic composite 3D structure of typical AEs and CEs in the AS with a zonal section across the eddy center. Eddies generally have maximal subsurface temperature deviations of more than $1.5^{\circ} \mathrm{C}$ (positive/negative for $\mathrm{AE} / \mathrm{CE})(\sim 120 \mathrm{~m})$. Similarly, AE/CE feature negative/positive density anomalies of approximately $0.3 \mathrm{~km} / \mathrm{m}^{3}$ centered at the same depth. This confirms the previous study that temperature primarily controls the density structure of eddies in the AS [Joseph and Freeland, 2005] and is consistent with the standard structures in stratified and rotating flows: $\mathrm{AE} / \mathrm{CE}$ force isopycnals to sink/rise to create negative/positive density anomalies

[Vallis, 2006]. 
Salinity anomalies inside $\mathrm{AE} / \mathrm{CE}$ are generally negative/positive, yet a layer with an opposite sign appears at the subsurface between 100 and $160 m$ (i.e., a saltier/fresher layer interrupts the negative/positive salinity anomalies inside the AE/CE), exhibiting a sandwich-like pattern, which was observed by Argo profiles in the region [de Marez et al., 2019]. Low salinity water was advected by the Somali and North Equatorial Currents into the AS [Morrison, 1997], and high salinity water formed in the northern basin and the Arabian Gulf sinks to the subsurface, yielding a subsurface layer of high salinity water which spreads over a large proportion of the basin [Rochford, 1964; Kumar and Prasad, 1999]. Precipitation and runoff in the eastern AS contribute to the local formation of low salinity waters, which augment the subsurface maximum [Joseph and Freeland, 2005]. Thus, AE-induced downwelling and CE-induced upwelling synergize an inverse "S" salinity profile structure (Figure 2 f) and create a three-core sandwich-like pattern. Similar prominent salinity profile structures were also reported in the north Pacific [Qiu and Chen, 2005], the subtropical Pacific [Yang et al., 2013a], and the South China Sea [Zhang et al., 2018].

The composite meridional rotational currents are surface-intensified and decreasing with depth. The largest velocities are found at approximately one radius from the eddy center, with maximum azimuthal speeds of more than $0.2 \mathrm{~m} / \mathrm{s}$ near the surface. Neither the T/S anomalies nor the rotation velocities are symmetric around the eddy core. Such asymmetry is crucial for inducing net swirl transport [Roemmich and Gilson, 2001]. AE and CE cause uplift and depression of the background pycnocline profiles, and the associated T/S anomalies with opposite signs could lead to distinct eddy drift transport features. 
$\mathrm{X}-10$ ZHAN ET AL.: EDDY TRANSPORT AND ENERGY BUDGET

\section{Eddy-induced transport}

We first investigate the averaged eddy swirl transport (S2) of heat and salt (Figure 3 a-d). Eddies generally produce stronger swirl transport in the western AS and GoA. Zonally, eddies yield eastward (positive) heat transport in the GoA and east off the Somali Cape towards the GoO. These processes are important for balancing the heat budget and to promote zonal heat exchange between coastal and ambient waters in the region [Fischer et al., 2002; de Marez et al., 2019]. The blue and purple patch east of Somalia (Figure 3 a) suggests strong westward and eastward heat transport with a large zonal temperature gradient persisting, particularly in summer as a result of Ekman pumping effect [Wilson-Diaz et al., 2009; Trott et al., 2017]. Northward (positive) meridional heat transport is found inside the GoA and along a $\sim 100 \mathrm{~km}$ band along the Somalia coast (Figure $3 \mathrm{~b}$ ); the more pronounced dark blue patch further east suggests large southward heat transport. The northward SC produces strong shear in velocity with its southward retroflection [Trott et al., 2019], generating eddies asymmetry in shape and T/S properties [Trott et al., 2019] and hence inducing intense swirl transport. Eddies in the region induce clockwise patterns of heat transport (indicated by the green arrows in Figure $3(\mathrm{a}, \mathrm{b})$ ), which tends to counteract the transport of upwelled water induced by the Somali cold current and its retroflection [Fischer et al., 2002; Volkov et al., 2008].

Zonal salt transport is positive (eastward) in the GoA, the GoO, and the eastern AS, whereas negative (westward) in the western AS. Precipitation and runoff from rivers in the eastern AS contribute to the local formation of low salinity waters [Joseph and Freeland, 2005], and eddy swirl transport tends to decrease the gradient by eastward salt

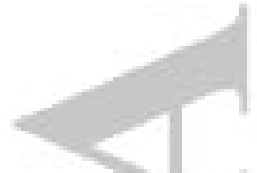

D R A F T
November 13, 2020, 5:28am
D R A F T 
flux. Additionally, high evaporation rates in the northern AS causes high surface salinity [Morrison, 1997]. This is compensated by eddy swirl transport with a negative meridional (southward) salt flux in the entire AS and equivalent northward freshwater transport. The only notable exception for meridional salt transport is inside the GoA, where eddies tend to transport saltier water northward.

Figure 3 (e-h) shows the averaged drift transport (S3). AEs and CEs normally propagate westwards with negative zonal velocities at similar speeds but feature opposite tracer displacement tendencies (Figure 2). Consequently, AEs and CEs produce opposite zonal transports and tend to offset each other; the total transport is smaller than that of either type alone. However, eddies can be coherently advected over regions with strong background currents and produce large drift transport. A typical example is in the western AS off Somalia, where AEs are larger and usually formed by the branches of the background currents (e.g. the GW), while CEs are smaller and more likely to be advected as a wellmaintained integral [Trott et al., 2018]. Consequently, the westward propagating cold-core CEs produce positive zonal heat transport (Figure 3 e). The meridional eddy drift transport in the interior basin is weak because of limited meridional propagation (Figure $1 \mathrm{i}$ ); however, the strong northward SC and southward retroflection can trap and advect eddies in the region (particularly CEs) to form heat transport in the opposite direction (Figure $3 \mathrm{f}$ ). The drift transport of salt is generally small (Figure $3 \mathrm{~g}$ and $\mathrm{h}$ ), largely because of multi-layer structure in salinity anomaly offset by trap depth integration.

From a global perspective, eddy meridional movement tends to transport heat and salt towards the equator in the tropics [Jayne and Marotzke, 2002; Volkov et al., 2008]. This

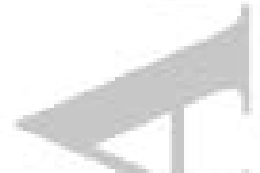

D $R A F$ T 
$\mathrm{X}-12$ ZHAN ET AL.: EDDY TRANSPORT AND ENERGY BUDGET

effect is evident in the interior $\mathrm{AS}$, where $\mathrm{T} / \mathrm{S}$ transports are negative (southward) but not significant. Our analysis suggests that meridional eddy drift transport in the basin is more influenced by background circulation (i.e. the SC and its extension). Meridional eddy drift transport of heat in these regions is at least one order larger than in the interior basin and exhibits patterns consistent with that of background flow.

Total eddy-induced transport is the sum of swirl and drift transport (Figure 3 i-p). Swirl transport generally exhibits larger magnitude, and the two types of transport have the same order and may synergize or compensate each other depending on location. As reported by Hastenrath and Greischar [1993]; Wilson-Diaz et al. [2009], the oceanic heat transport to the AS switches between seasons (northward in winter while southward in summer). The annual average of heat transport is $\sim 105 T W$ across the $6^{\circ} \mathrm{N}$ section, out of which about $15 \%(\sim 16 T W)$ is contributed by eddies that transport heat southward throughout the year. Positive zonal T/S transport within the GoA suggests that eddies transport cooler, fresher water to the western end of the GoA, a process that actively spreads Red Sea outflow and generates large T/S gradients to form favorable conditions for fingering and diffusive convection [Bower and Furey, 2012]. Positive meridional heat transport in the gulf further suggests that eddies are important transporters of warmer water towards the northern coast and moderators of the summer Ekman upwelled thermocline [Yao and Hoteit, 2015]. Eddies also transport warmer, saltier water outflow from the Arabian Gulf eastward into GoO, as evidenced by in-situ observations [L'Hegaret et al., $2016]$

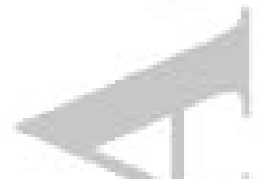

D R A F T

November 13, 2020, 5:28am

D R A F T 
Additionally, SST data indicate that eddies may sometimes transport coastal upwelled water offshore of Somalia with filament structures on the surface [Fischer et al., 2002]. A close-up of the cross section reveals similar statistical features with negative zonal heat transport in the uppermost layers (Figure $3 \mathrm{~m}$, equivalent to eastward transport of colder water). However, the larger heat flux is contributed by the subsurface layer where heat is transported in the opposite direction. Eddies in the SC region generally have deeper structures than those of the interior basin and have deeper penetration cores between 100$200 \mathrm{~m}$. In the meridional direction, eddies transport heat northward in the upper layers, whereas thicker deeper layers produce southward heat transport with maximal values at $\sim 180 \mathrm{~m}$

Furthermore, circulation is not fully aligned with the isothermal, and it is the crossisothermal component that directly contributes to heat exchange between water parcels. We estimated the cross-isothermal heat transport of mean flow and eddy flow by projecting their velocities onto the direction of temperature gradient, i.e.,

$$
Q_{\text {heat,cross-iso }}=\rho C_{p} T \mathbf{u}_{\mathbf{h}} \cdot\left(\nabla_{h} T /\left|\nabla_{h} T\right|\right) \text {. }
$$

The basin-integrated $Q_{\text {heat,cross-iso }}$ by mean flow is down-gradient (from warmer to colder water) in winter while up-gradient (from colder to warmer water) in summer. The variability offsets between seasons and yields an annual average of $\sim 2.1 P W$ up-gradient transport integrated over the entire AS. In contrast, this is over-compensated by the eddy-induced

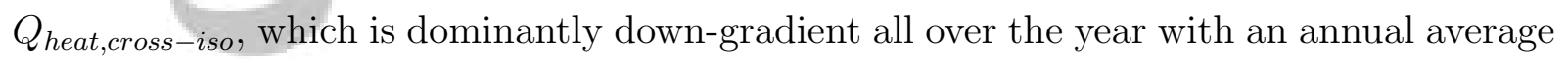
of $\sim 5.2 P W$. This agrees with the general Fickian-like form hypothesis [Stammer, 1998] where eddy transport is assumed down-gradient, and it can be explained by diagnosing 
$\mathrm{X}-14$

the baroclinic energy conversion [Brooks and Niiler, 1977; Jayne and Marotzke, 2002]

$$
-\overline{\rho^{\prime} w^{\prime}} g=\frac{g}{|\partial \bar{\rho} / \partial z|}\left(\overline{\rho^{\prime} u^{\prime}} \frac{\partial \bar{\rho}}{\partial x}+\overline{\rho^{\prime} v^{\prime}} \frac{\partial \bar{\rho}}{\partial y}\right)
$$

which, if neglecting the salinity effect under reasonably constant stratification, reduces to

$$
-\overline{T^{\prime} \mathbf{u}_{\mathbf{h}}^{\prime}} \cdot\left(\nabla_{h} \bar{T}\right)
$$

This suggests that eddies tend to transport heat down-gradient when baroclinic energy is converted from mean flow to eddy fields $\left(-\overline{\rho^{\prime} w^{\prime}} g>0\right)$, which is proved true for the AS as discussed in the next section. Following a similar approach, we estimate the cross-isosaline transport using

$$
Q_{\text {salt }, \text { cross-iso }}=\rho S \mathbf{u}_{\mathbf{h}} \cdot\left(\nabla_{h} S /\left|\nabla_{h} T\right|\right) .
$$


$\mathrm{X}-16$ ZHAN ET AL.: EDDY TRANSPORT AND ENERGY BUDGET

AS, particularly during summer. Meanwhile, eddy-induced vertical salt fluxes exhibit a seasonal variability that is downward during winter and upward during summer (Figure 4 $\mathrm{b}$ and $\mathrm{g}$ ). The annual average is downward of $\sim 3.7 \times 10^{5} \mathrm{~kg} / \mathrm{s}$, accounting for only $\sim 3 \%$ of the total downward salt transport.

\section{Origins of Eddy Kinetic Energy}

We further investigate the origins of EKE in the AS by diagnosing the complete 3D energy budget (S4), with a particular focus on eddy energy generation. Obvious differences are discernible among the energy flux terms between winter and summer corresponding to seasonal EKE variability (Figure 5$)$. The ubiquitously positive values of $\mathrm{T} 1\left(-\overline{\rho^{\prime} w^{\prime}} g\right)$ suggest that eddy potential energy is released via baroclinic instability across the AS (necessary conditions for baroclinic instability are satisfied, not shown). In particular, maximal values were identified east of Somalia in summer (1st column of Figure 5), when the strong southwesterly monsoon causes upwelling along the Somalia coast. The uplifted isopycnal is tilted downslope towards the east (Figure $5 \mathrm{t}$ ), preconditioning baroclinic instability that peaks from 50-180 $\mathrm{m}$. This term usually follows the location of the mean lateral density gradients, as expected from the linear instability theory [Green, 1970]. The pycnocline is flatter in the interior basin, particularly in winter, and therefore limits EKE production.

Another source term, T5 $\left(\rho_{0} \overline{\mathbf{u}_{h}^{\prime} \cdot\left(\mathbf{u}^{\prime} \cdot \nabla \overline{\mathbf{u}_{h}}\right)}\right)$, presents larger amplitudes in summer east of Somalia (2nd column of Figure 5). Positive T5 implies KE transfer from mean flow to eddies, agreeing with the analysis of EKE associated with the Southern Gyre [Chatterjee et al., 2013]. The large horizontal velocity shear in summer enhances barotropic instability, 
direct generation of EKE through turbulent wind being positive in the entire AS (Figure 5 e and j). This agrees with global open oceans [Von Storch et al., 2012] and other marginal seas [Pujol and Larnicol, 2005; Chen et al., 2009; Zhan et al., 2018; Chen et al., 2016, 2018], yet the magnitude over the AS is about one order smaller than major regions of high EKE as discussed above. Meanwhile, although the eastern basin exhibits much weaker EKE, more than $50 \%$ of which is contributed by the direct wind stress, making it the primary energy source over the large eastern basin. In comparison, winds' contribution is one order smaller than the oceanic internal instabilities in the $\mathrm{SC}$ region, particularly during summer.

Furthermore, to compare the EKE production at different geographic locations, the AS is divided into five sub-regions as shown in Figure $5(\mathrm{u})$, where A, B, C, D, E respond to the Gulf of Aden, Gulf of Oman, northwestern AS, southwestern AS, and eastern AS, respectively. The corresponding domain averaged EKE flux terms are illustrated in Figure $5(\mathrm{v})$ for winter and (w) for summer (note difference in their vertical scales). During winter, the EKE is predominantly produced by baroclinic instability and wind stress across the entire AS, with those in the western basin two times larger than the eastern basin. During summer, the southwestern AS (sub-region D) is noticeably distinguished by the elevated EKE production rate about five times higher than others, primarily contributed by barotropic and baroclinic instabilities, while the EKE sources in the other sub-regions are attributed by baroclinic instability and wind at a similar level. In both seasons, the negative values of $\mathrm{T} 2$ and $\mathrm{T} 3+\mathrm{T} 4$ suggest that EKE propagates into deep ocean and more significantly, into coastal (shallower) regions.

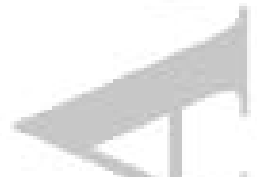

D R A F T
November 13, 2020, 5:28am
D R A F T 


\section{Summary}

Most previous studies for the AS concentrate on larger-scale circulations or particular eddies, using sparse observations or coarser-resolution models. In this study we focused on an unexplored aspect that was poorly understood before, the spacial-temporal variability of eddy-induced transport and eddy energy budget, based on a high-resolution global reanalysis product. In addition, this study identifies one new hotspot in the global ocean with noticeable upward eddy-induced heat transport, and offers a new perspective on the dynamics sustaining the SST fronts in the western AS during summer.

The AS exhibits pronounced intraseasonal and spatial variability in eddy activity. Elevated EKE exhibits during summer, primarily east of the Somalia coast. Composite maps show $\mathrm{AE} / \mathrm{CE}$ can induce warm/cold temperature anomalies with an intensified subsurface magnitude where a single-core appears at approximately $100 \mathrm{~m}$. Salinity anomalies are intensified at the surface with an interleaved sandwich-like structure. Eddies-induce swirl and drift transports are estimated based on detected individual eddies and their tracks. The analysis of a complete heat/salt budget is beyond the scope of this study, but important insights are gained by investigating the horizontal and vertical $\mathrm{T} / \mathrm{S}$ transport due to mecoscale eddies, which is a key component that modulates the heat and salt content in the western AS. In general, eddy currents affect flux of heat more than salt. The swirl component was generally larger than the drift component in the west AS, yet their magnitude are comparable in the interior basin. The overall cross-iso eddy-induced $\mathrm{T} / \mathrm{S}$ transports in the AS are both down-gradient, in which the total cross-isothermal transport of mean flow is over compensated by eddies. Eddies also produce vertical heat and

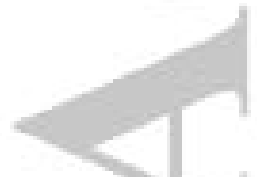

D R A F T

November $13,2020,5: 28 \mathrm{am}$

D R A F T 
$\mathrm{X}-20$ ZHAN ET AL.: EDDY TRANSPORT AND ENERGY BUDGET 
Stronger power input is produced from time-mean winds and circulation [ Von Storch et al., 2012], and the net conversion from MKE to EKE indicates a power pathway from winds to time-mean circulation and, eventually, to time-varying eddy circulation.

Acknowledgments. The research reported in this manuscript was supported by King Abdullah University of Science and Technology (KAUST) and Saidu ARAMCO-KAUST Marine Environmental Observatory (SAKMEO). The research and made use of the resources of the Supercomputing Laboratory and computer clusters at KAUST. This study has been conducted using E.U. Copernicus Marine Service Information data available at ftp://my.cmems-du.eu/Core/ and ECMWF product available at https://www.ecmwf.int/en/forecasts/datasets/archivedatasets. The data supporting the analysis presented here can be found at Figshare (https://figshare.com/articles/dataset/AS_EKE/12846587). 
$\mathrm{X}-22$ ZHAN ET AL.: EDDY TRANSPORT AND ENERGY BUDGET

\section{References}

Al Saafani, M. A., S. S. Shenoi, D. Shankar, M. Aparna, J. Kurian, F. Durand, and P. N. Vinayachandran (2007), Westward movement of eddies into the Gulf of Aden from the Arabian Sea, Journal of Geophysical Research: Oceans, doi:10.1029/2006JC004020.

Beal, L. M., V. Hormann, R. Lumpkin, and G. R. Foltz (2013), The response of the surface circulation of the arabian sea to monsoonal forcing, Journal of Physical Oceanography, doi:10.1175/JPO-D-13-033.1.

Bower, A. S., and H. H. Furey (2012), Mesoscale eddies in the Gulf of Aden and their impact on the spreading of Red Sea Outflow Water, Progress in Oceanography, doi: 10.1016/j.pocean.2011.09.003.

Brandt, P., L. Stramma, F. Schott, J. Fischer, M. Dengler, and D. Quadfasel (2002), Annual Rossby waves in the Arabian Sea from TOPEX/POSEIDON altimeter and in situ data, Deep-Sea Research Part II: Topical Studies in Oceanography, doi:10.1016/S09670645(01)00166-7.

Brooks, I. H., and P. P. Niiler (1977), ENERGETICS OF THE FLORIDA CURRENT., Journal of Marine Research.

Carton, X., P. L'Hegaret, and R. Baraille (2012), Mesoscale variability of water masses in the Arabian Sea as revealed by ARGO floats, Ocean Science, doi:10.5194/os-8-227-2012.

Chatterjee, A., D. Shankar, J. P. McCreary, and P. N. Vinayachandran (2013), Yanai waves in the western equatorial Indian Ocean, Journal of Geophysical Research: Oceans, doi:10.1002/jgrc.20121. 
Chelton, D. B., P. Gaube, M. G. Schlax, J. J. Early, and R. M. Samelson (2011), The influence of nonlinear mesoscale eddies on near-surface oceanic chlorophyll, Science, doi:10.1126/science.1208897.

Chen, G., Y. Hou, X. Chu, P. Qi, and P. Hu (2009), The variability of eddy kinetic energy in the South China Sea deduced from satellite altimeter data, Chinese Journal of Oceanology and Limnology, doi:10.1007/s00343-009-9297-6.

Chen, G., J. Gan, Q. Xie, X. Chu, D. Wang, and Y. Hou (2012), Eddy heat and salt transports in the South China Sea and their seasonal modulations, Journal of Geophysical Research: Oceans, doi:10.1029/2011JC007724.

Chen, G., W. Han, Y. Li, and D. Wang (2016), Interannual variability of equatorial eastern Indian Ocean upwelling: Local versus remote forcing, Journal of Physical Oceanography, doi:10.1175/JPO-D-15-0117.1.

Chen, G., Y. Li, Q. Xie, and D. Wang (2018), Origins of Eddy Kinetic Energy in the Bay of Bengal, Journal of Geophysical Research: Oceans, doi:10.1002/2017JC013455.

de Marez, C., P. L'Hégaret, M. Morvan, and X. Carton (2019), On the 3D structure of eddies in the Arabian Sea, Deep-Sea Research Part I: Oceanographic Research Papers, doi:10.1016/j.dsr.2019.06.003.

Dong, C., J. C. McWilliams, Y. Liu, and D. Chen (2014), Global heat and salt transports by eddy movement, Nature Communications, doi:10.1038/ncomms4294.

Dong, S., and K. A. Kelly (2004), Heat budget in the Gulf Stream region: The importance of heat storage and advection, Journal of Physical Oceanography, doi:10.1175/15200485(2004)034¡1214:HBITGS¿2.0.CO;2.

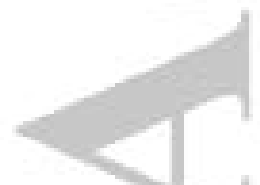


$\mathrm{X}-24$ ZHAN ET AL.: EDDY TRANSPORT AND ENERGY BUDGET 
$\mathrm{X}-26$ ZHAN ET AL.: EDDY TRANSPORT AND ENERGY BUDGET 
Seo, H. (2017), Distinct influence of air-sea interactions mediated by mesoscale sea surface temperature and surface current in the Arabian Sea, Journal of Climate, doi: 10.1175/JCLI-D-16-0834.1.

Seo, H., R. Murtugudde, M. Jochum, and A. J. Miller (2008), Modeling of mesoscale coupled ocean-atmosphere interaction and its feedback to ocean in the western Arabian Sea, Ocean Modelling, doi:10.1016/j.ocemod.2008.07.003.

Sergey, P. (2012), Mesoscale Eddies of Arabian Sea: Physical-biological Interactions, International Journal of Marine Science, doi:10.5376/ijms.2012.02.0007.

Sharma, R., A. K. Gopalan, and M. M. Ali (1999), Interannual variation of eddy kinetic energy from topex altimeter observations, Marine Geodesy, doi:10.1080/014904199273371.

Souza, J. M., C. De Boyer Montégut, C. Cabanes, and P. Klein (2011), Estimation of the Agulhas ring impacts on meridional heat fluxes and transport using ARGO floats and satellite data, Geophysical Research Letters, doi:10.1029/2011GL049359.

Stammer, D. (1998), On eddy characteristics, eddy transports, and mean flow properties, Journal of Physical Oceanography, doi:10.1175/15200485(1998)028;0727:OECETA¿2.0.CO;2.

Stammer, D., and C. Wunsch (1999), Temporal changes in eddy energy of the oceans, Deep-Sea Research Part II: Topical Studies in Oceanography, doi:10.1016/S09670645(98)00106-4.

Sun, B., C. Liu, and F. Wang (2019), Global meridional eddy heat transport inferred from Argo and altimetry observations, Scientific Reports, doi:10.1038/s41598-018-38069-2. 
$\mathrm{X}-28$ ZHAN ET AL.: EDDY TRANSPORT AND ENERGY BUDGET

Trott, C. B., B. Subrahmanyam, and V. S. Murty (2017), Variability of the Somali Current and eddies during the southwest monsoon regimes, Dynamics of Atmospheres and Oceans, doi:10.1016/j.dynatmoce.2017.07.002.

Trott, C. B., B. Subrahmanyam, A. Chaigneau, and T. Delcroix (2018), Eddy Tracking in the Northwestern Indian Ocean During Southwest Monsoon Regimes, Geophysical Research Letters, doi:10.1029/2018GL078381.

Trott, C. B., B. Subrahmanyam, A. Chaigneau, and H. L. Roman-Stork (2019), EddyInduced Temperature and Salinity Variability in the Arabian Sea, Geophysical Research Letters, doi:10.1029/2018GL081605.

Vallis, G. K. (2006), Atmospheric and Oceanic Fluid Dynamics, doi: $10.1017 / \operatorname{cbo} 9780511790447$.

Vivier, F., K. A. Kelly, and L. A. Thompson (2002), Heat budget in the Kuroshio extension region: 1993-99, Journal of Physical Oceanography, doi:10.1175/15200485(2002)032¡3436:HBITKE¿2.0.CO;2.

Volkov, D. L., T. Lee, and L. L. Fu (2008), Eddy-induced meridional heat transport in the ocean, Geophysical Research Letters, doi:10.1029/2008GL035490.

Von Storch, J. S., C. Eden, I. Fast, H. Haak, D. Hernández-Deckers, E. Maier-Reimer, J. Marotzke, and D. Stammer (2012), An estimate of the Lorenz energy cycle for the World Ocean based on the $1 / 10^{\circ}$ STORM/NCEP simulation, Journal of Physical Oceanography, doi:10.1175/JPO-D-12-079.1.

Wang, H., J. L. McClean, L. D. Talley, and S. Yeager (2018), Seasonal Cycle and Annual Reversal of the Somali Current in an Eddy-Resolving Global Ocean Model, Journal of 
Geophysical Research: Oceans, doi:10.1029/2018JC013975.

Wilson-Diaz, D., A. J. Mariano, and R. H. Evans (2009), On the heat budget of the Arabian Sea, Deep-Sea Research Part I: Oceanographic Research Papers, doi: 10.1016/j.dsr.2008.09.003.

Yang, G., F. Wang, Y. Li, and P. Lin (2013a), Mesoscale eddies in the northwestern subtropical Pacific Ocean: Statistical characteristics and three-dimensional structures, Journal of Geophysical Research: Oceans, doi:10.1002/jgrc.20164.

Yang, H., L. Wu, H. Liu, and Y. Yu (2013b), Eddy energy sources and sinks in the South China Sea, Journal of Geophysical Research: Oceans, 118(9), 4716-4726, doi: 10.1002/jgrc.20343.

Yang, H., J. Liu, G. Lohmann, X. Shi, Y. Hu, and X. Chen (2016), Ocean-atmosphere dynamics changes associated with prominent ocean surface turbulent heat fluxes trends during 19582013, Ocean Dynamics, doi:10.1007/s10236-016-0925-3.

Yao, F., and I. Hoteit (2015), Thermocline regulated seasonal evolution of surface chlorophyll in the Gulf of Aden, PLoS ONE, doi:10.1371/journal.pone.0119951.

Zhan, P., A. C. Subramanian, F. Yao, A. R. Kartadikaria, D. Guo, and I. Hoteit (2016), The eddy kinetic energy budget in the Red Sea, Journal of Geophysical Research: Oceans, 121(7), 4732-4747, doi:10.1002/2015JC011589.

Zhan, P., G. Gopalakrishnan, A. C. Subramanian, D. Guo, and I. Hoteit (2018), Sensitivity Studies of the Red Sea Eddies Using Adjoint Method, Journal of Geophysical Research: Oceans, O(ja), doi:10.1029/2018JC014531. 
Zhan, P., G. Krokos, D. Guo, and I. Hoteit (2019), Three-Dimensional Signature of the Red Sea Eddies and Eddy-Induced Transport, Geophysical Research Letters, doi: 10.1029/2018GL081387.

Zhang, W. Z., Q. Ni, and H. Xue (2018), Composite eddy structures on both sides of the Luzon Strait and influence factors, Ocean Dynamics, doi:10.1007/s10236-018-1207-z.

Zhang, Z., Y. Zhang, W. Wang, and R. X. Huang (2013), Universal structure of mesoscale eddies in the ocean, Geophysical Research Letters, doi:10.1002/grl.50736.

Zhang, Z., W. Wang, and B. Qiu (2014), Oceanic mass transport by mesoscale eddies, Science, doi:10.1126/science.1252418.
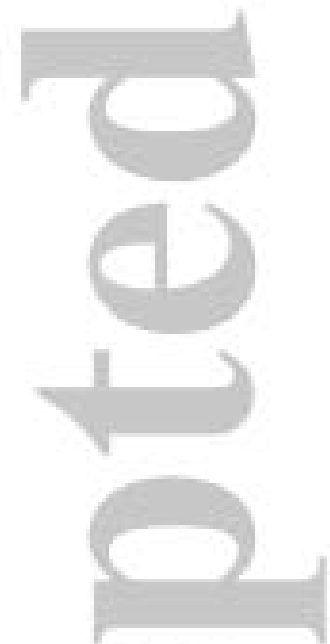

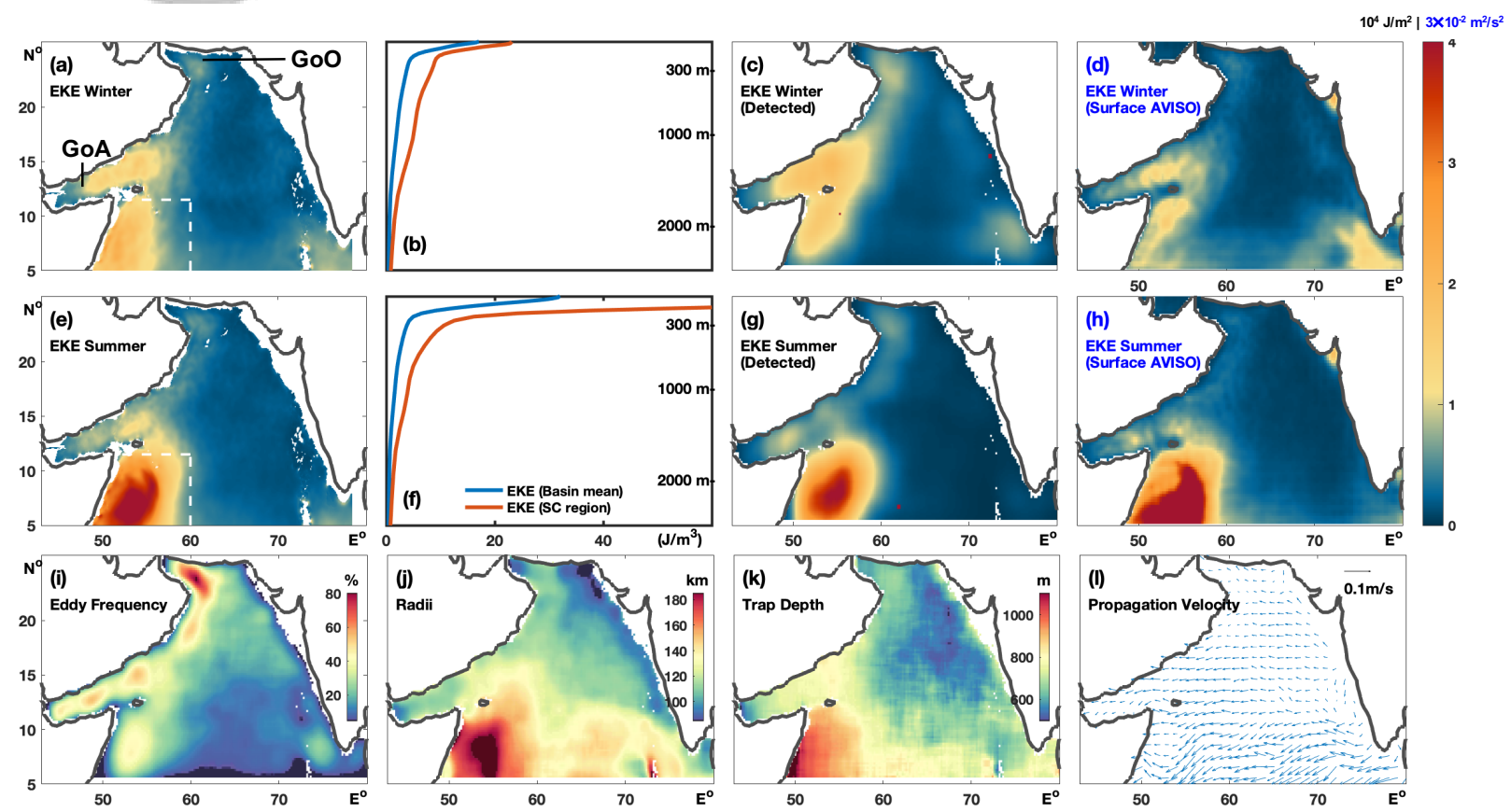

Figure 1. Distribution of energy quantities in winter (upper panel) and summer (middle panel): (a/e) vertically integrated $E K E\left(\frac{1}{2} \rho\left(u^{\prime 2}+v^{\prime 2}\right)\right),(\mathrm{b} / \mathrm{f})$ vertically averaged EKE profile of basin (blue) and SC region (red, defined in a and e), (c/g) vertically integrated EKE estimated from detected eddies, $(\mathrm{d} / \mathrm{h})$ surface $E K E\left(\frac{1}{2} \rho\left(u^{\prime 2}+v^{\prime 2}\right)\right)$ estimated from AVISO altimetry data. The arrows in $(\mathrm{b} / \mathrm{f})$ depict the vertically averaged velocity in winter/summer. Distribution of detected eddies properties: (i) eddy frequency, (j) eddy radius, (k) eddy trap depth, (l) eddy propagation speed. 

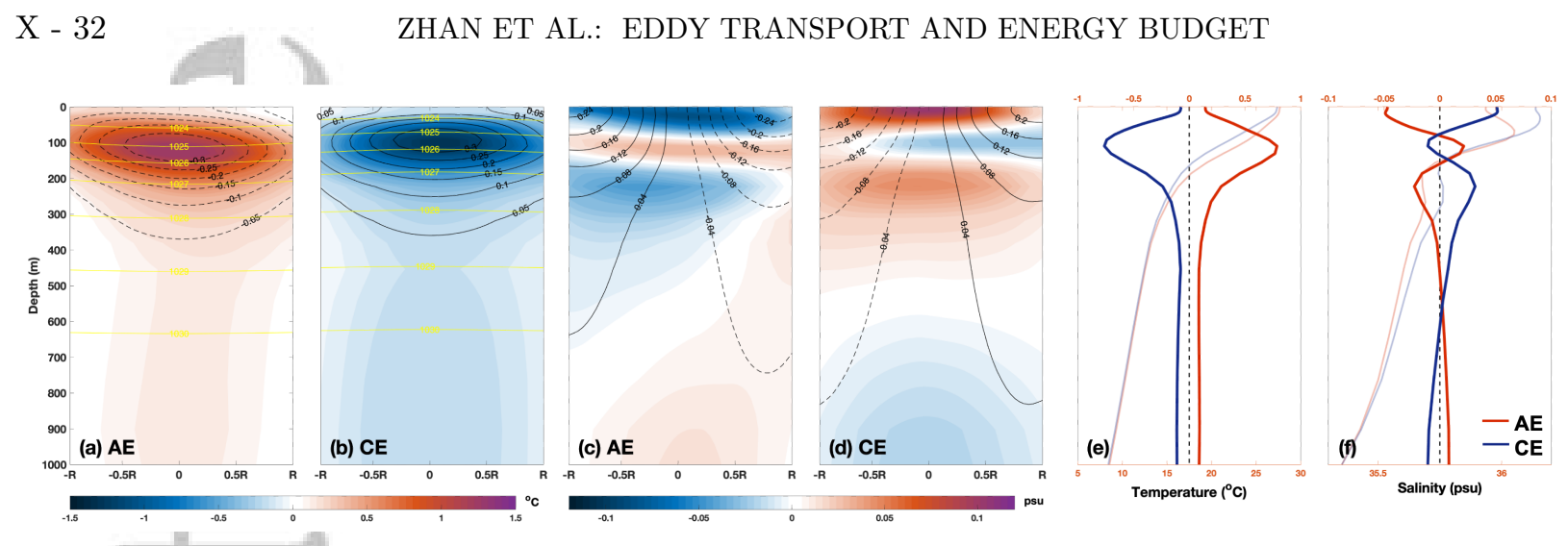

Figure 2. Composite zonal sections of vertical structure across the anticyclonic eddy (a, c) and cyclonic eddy (b, d). In (a, b), the composite temperature anomaly, density anomaly, mean density are depicted with color shading, black dotted line and yellow solid line, respectively. In (c, d) the composite salinity anomaly, positive meridional (northward) velocity, negative meridional (southward) velocity are depicted with color shading, black solid line and black dotted line, respectively. Averaged profiles of temperature (e) and salinity (f) within AE (red) and CE (blue), where dark and light lines depict anomalies and mean values, respectively. 

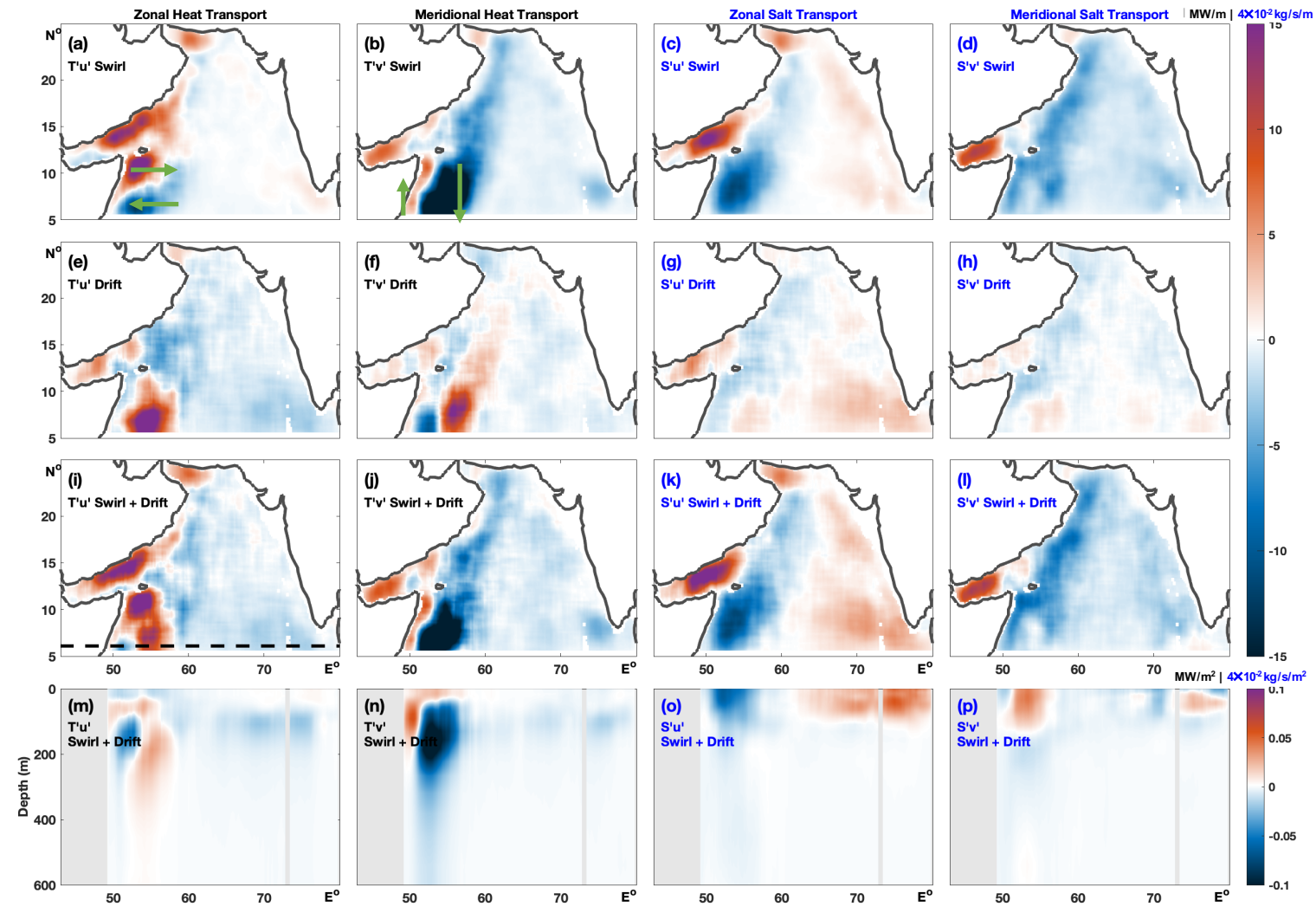

Figure 3. Distribution of vertically integrated eddy-induced transport, the left to right columns illustrate zonal heat transport, meridional heat transport, zonal salt transport and meridional salt transport, respectively. The 1st (a-d), 2nd (e-h), and 3rd (i-l) rows show eddy swirl transport due to rotation, eddy drift transport due to propagation, and total transport, respectively. The bottom row (m-p) shows the corresponding vertical distribution of total transport at the cross section of $8^{\circ} \mathrm{N}$ indicated by the dotted black line in (i). 


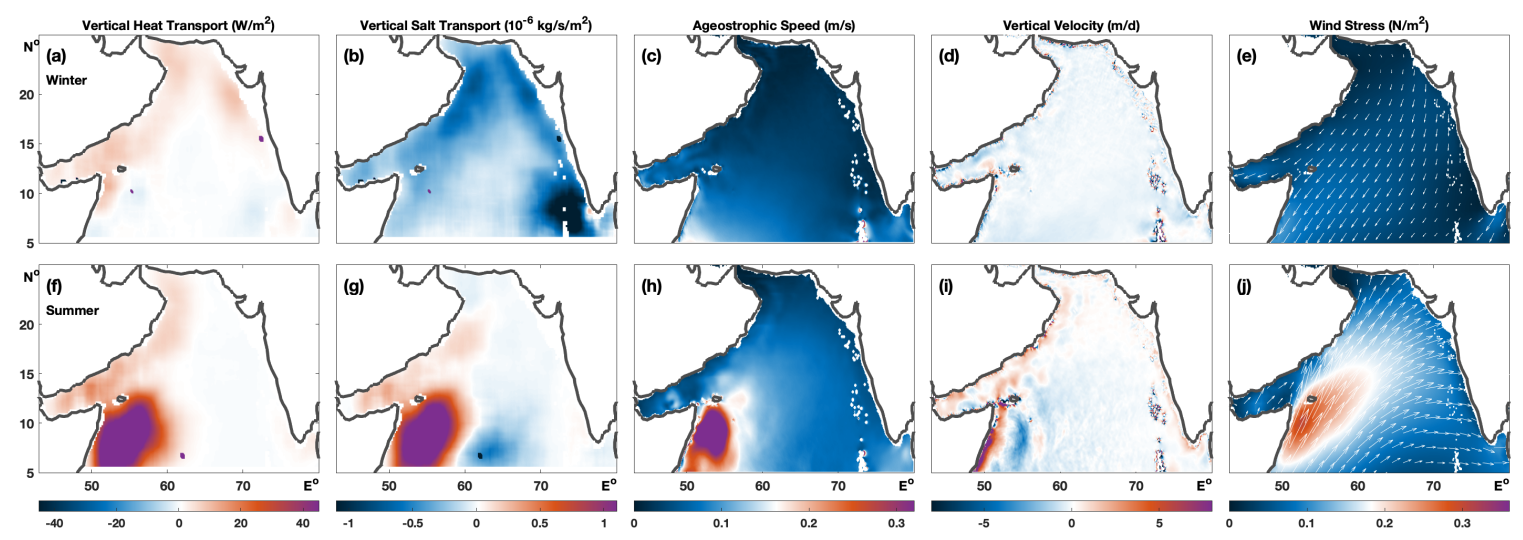

Figure 4. Eddy-induced vertical transport of heat (a and f) and salt (b and g), magnitude of ageostrophic velocity (c and h), and magnitude of vertical velocity ( $\mathrm{d}$ and i) at the depth of $50 \mathrm{~m}$. This depth is chosen within which the ocean is almost always well mixed. Surface wind stress (e and j) in arrows and their magnitude in color. The upper and lower panels represent the distributions in averaged in winter and summer, respectively. 


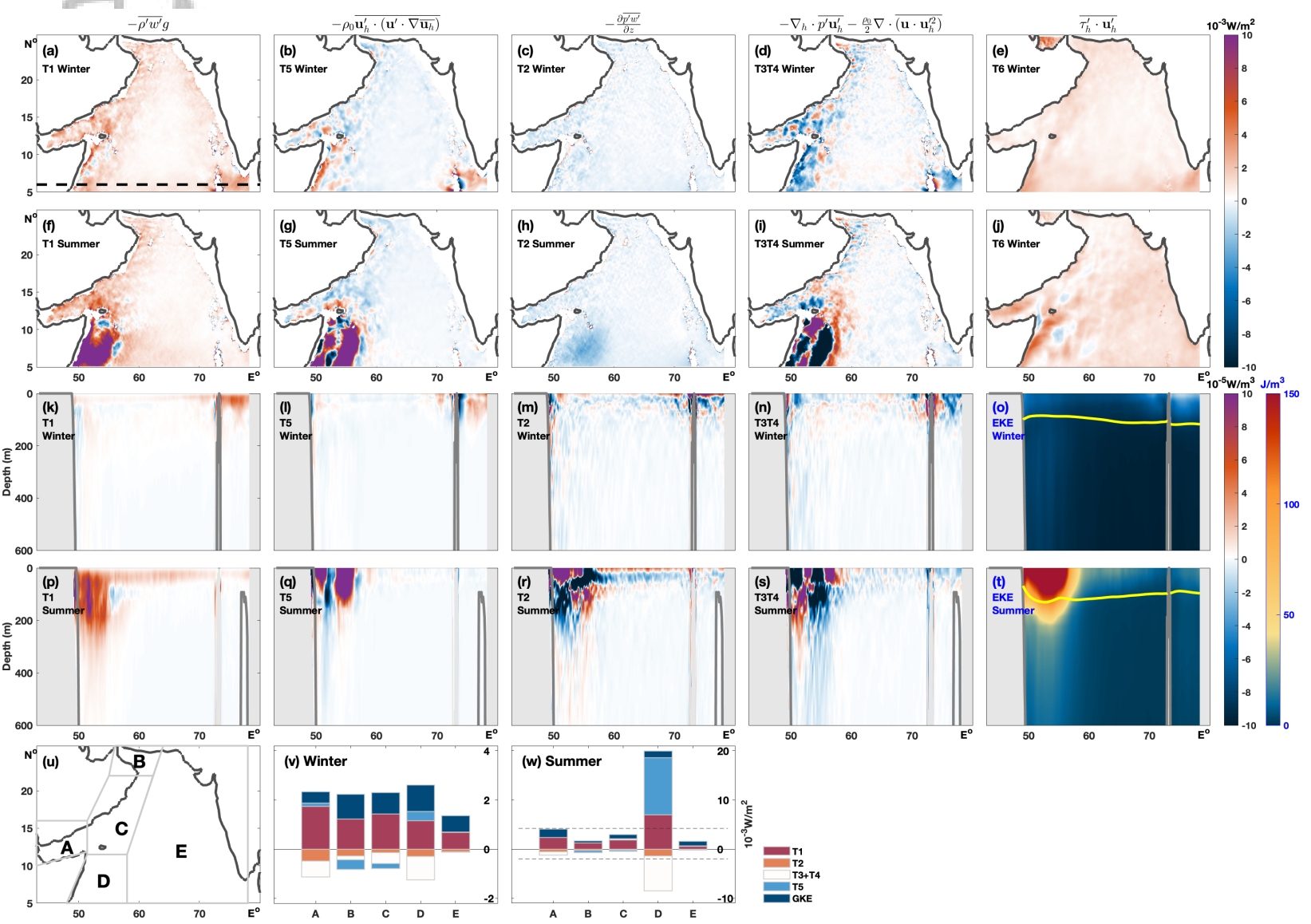

Figure 5. Eddy energy flux terms $\left(-\overline{\rho^{\prime} w^{\prime}} g(\mathrm{~T} 1),-\rho_{0} \overline{\mathbf{u}_{h}^{\prime} \cdot\left(\overline{\mathbf{u}^{\prime} \cdot \nabla \overline{\mathbf{u}_{h}}}\right)}(\mathrm{T} 5),-\frac{\partial \overline{p^{\prime} w^{\prime}}}{\partial z}(\mathrm{~T} 2)\right.$ $\left.-\nabla_{h} \cdot \overline{p^{\prime} \mathbf{u}_{h}^{\prime}}-\frac{\rho_{0}}{2} \nabla \cdot \overline{\left(\mathbf{u} \cdot \mathbf{u}_{h}^{\prime 2}\right)}(\mathrm{T} 3 \mathrm{~T} 4)\right)$ integrated in the upper $1200 \mathrm{~m}$ averaged for winter (a-d) and summer (f-j), and the corresponding vertical structure along the cross section marked by the dashed line in (a) for winter (k-n) and summer (o-r). Distribution of generation of EKE due to surface power input by time-varying wind $\left(\overline{\mathbf{u}_{h}^{\prime} \cdot \tau_{h}^{\prime}}\right)$ in winter (e) and summer (j). Vertical structure of EKE along the cross section in winter (o) and summer (t), where the yellow solid lines depict the isopycnic of $1025 \mathrm{~kg} / \mathrm{m}^{3}$. Five subregions $(\mathrm{u})$ of the AS and the corresponding domain averaged EKE flux terms in winter (v) and summer (w). 